\title{
En Mar del Plata y en Hong Kong, "la batalla económica que se avecina"
}

\author{
Francisco Javier IBISATE \\ Departamento de Economía \\ $U C A$, San Salvador
}

RESUMEN: En la cumbre de la OMC en Hong Kong, volverán a discutirse los puntos pendientes de la reunión celebrada en 2001. Las cumbres de la OMC siguen siendo una dura batalla económica entre los países ricos y los paises emergentes. Dados los fracasos de las cumbres de Seattle y de Cancún, la reunión de Hong Kong viene con presagios de confrontación.

ABSTRACT: The issues that were postponed during the WTO Summit in 2001 will be discussed in the Hong Kong Summit. WTO Summits are tumed into a barsb economic struggle among rich and emerging countries. Due to the failures in the Seattle and Cancuin Summits, economic confrontation can be expected.

\section{Prefacio}

El presente artículo se inspira en el título de la obra de Lester Thurow, Head to bead, cuyo subtítulo español anuncia "La guerra del siglo XXI. La batalla económica que se avecina entre Japón, Europa y Estados Unidos". Del 13 al 18 de diciembre de 2005 se celebrará la cumbre de la $\mathrm{OMC}$ en Hong Kong, donde volverán a discutirse los puntos pendientes de la OMC de Doha-Qatar, 2001, que siguen siendo una dura batalla 
económica. En la reunión de Hong Kong se hará presente el fantasma de las cumbres de Seattle 1999 y Cancún 2003, que fueron un fiasco para la OMC. Algunos primeros artículos nos hacen presagiar que en Hong Kong también se repetirá una dura batalla; varias ONG hablan de consternación, decepción y de traición a los temas del ciclo de Doha. Nueve países emergentes y en desarrollo parecen estar dispuestos a blandir el hacha de guerra. Ahora el subtítulo de Head to head amenaza sobre todo el Tercer Mundo.

El pasado 24 de noviembre, La Prensa Gráfica traslada un breve comentario de Lula da Silva: "Menos ideologías, más acciones ALCA: Lula". El mandatario brasileño dijo que las discusiones del Área del Libre Comercio de las Américas deben ser sacadas del terreno ideológico, y ratificó su interés por negociar los capítulos sensibles en la OMC de Hong Kong: "El ALCA se convirtió en un debate ideológico y se dice que el que está en contra es de izquierda y el que está a favor es de derecha. Es un debate loco".

A comienzos de 2006 tal vez se dé inicio a nuestro TLC entre Centroamérica y Estados Unidos, que, en sentido geográfico, sería una parcela del ALCA; sin embargo, quisiera mostrar que difieren sustancialmente la forma y el contenido de ambos programas comerciales. Se ha tratado de difuminar el carácter confrontativo que encierra nuestro 'Tratado de Libre Comercio, pero 'la paz violenta' se hará presente desde el próximo año. En este artículo se presentan tres momentos cronológicos del ALCA, vistos a continuación en el escenario del actual entorno económico mundial y de las recientes cumbres de la OMC, tratando de mostrar que el llamado libre comercio internacional sigue siendo un mosaico de relaciones asimétricas. Es una forma de prepararnos a iniciar nuestro TLC, que también será parte de "la batalla económica que se avecina entre Estados Unidos y Centroamérica". Es triste escribir sobre una historia que presagia terminar mal, porque las cumbres de la OMC son una pasión sin presagios de resurrección. Con razón dijo Joseph Stiglitz que "la teoría del libre comercio es un fraude intelectual".

\section{Mar del Plata: Un documento final}

En la IV Cumbre de las Américas surge la confrontación al tratar un tema que no era punto de agenda: el Área del Libre Comercio de las Américas. "Dos días de reuniones no han servido para llegar a un acuerdo sobre un tema que ni siquiera estaba en el orden de la reunión, pero que 
se ha convertido en centro de todas discusiones". Se va a tratar de salvar esta cumbre redactando un documento final cuando algunos jefes de Estado ya regresaban a sus casas. (El Pais, 5 de noviembre de 2005) "Cuando se me invitó a esta reunión, había tres temas a discutir durante las 24 horas: el empleo, el empleo y el empleo. En ninguna parte se hacía mención del ALCA", afirmó el presidente Lula da Silva. "Nos hemos enfrentado con dignidad hasta el último momento" y MERCOSUR ha mostrado "su fuerza", declaró el anfitrión argentino Néstor Kirchner. "Esto ha sido algo inédito para una cumbre. Durante siete años jamás habíamos tenido un debate con la intensidad, profundidad y franqueza que han caracterizado estas cinco horas de discusiones", agregó Hugo Chávez. ("George W. Bush no logró relanzar el ALCA en la Cumbre de las Américas". Le Monde, 6 de noviembre de 2005)

Una vez clausurada oficialmente la cumbre, los países americanos han decidido proponer el punto más polémico sobre el que no han llegado a un acuerdo, el ALCA. "Los dinigentes han decidido afrontar de nuevo el tema tras la cumbre de la OMC que se celebrará el próximo mes en Hong Kong, según adelantó el presidente chileno Ricardo Lagos. El presidente chileno indicó que el documento final de la IV Cumbre de las Américas recoge las dos posiciones que no lograron conciliarse: que se fije ahora una fecha para reanudar la negociación sobre el ALCA y la que consideraba que no están dadas las condiciones para ello. Las deliberaciones, del grupo técnico de trabajo primero, de los cancilleres el jueves y de los presidentes el viernes y sábado, se caracterizaron por las discrepancias sobre la reactivación del proyecto del Área del Libre Comercio de las Américas. A esta iniciativa, impulsada por Estados Unidos y sus aliados, se oponían los países del MERCOSUR (Argentina, Brasil, Paraguay, Uruguay) y Venezuela de manera tajante. El lanzamiento del ALCA fue el motivo de la I Cumbre de las Américas, celebrada en diciembre de 1994 en Miami, EE.UU., y estaba previsto que el proyecto se pusiera en marcha este año, 2005, con la apertura gradual de las barreras aduaneras entre 34 países americanos, excepto Cuba, que fue excluido. Pero once años después de su lanzamiento, el proyecto está paralizado a causa de la persistencia de los subsidios a la agricultura que aplican Estados Unidos y otras potencias y cuya anulación reclama MERCOSUR". Veremos que no es ésta la única y principal causa del estancamiento del ALCA. ("Reuniones de última hora tratan de salvar la cumbre de las Américas". El Mundo, Madrid, 5 de noviembre de 2005) 
El presidente de México, Vicente Fox, manifestó no estar "nada satisfecho" con el borrador de la declaración final y advirtió que, dado que hay 29 países dispuestos, el ALCA podría ponerse en marcha sin los miembros de MERCOSUR, opuestos a la iniciativa, invitándoles a ser "más creativos" y regresar a la mesa de las negociaciones. El ministro brasileño de Asuntos Exteriores, Celso Amorim, aseguró que "Brasil no quiere enterrar el ALCA, pero sí construirlo sobre bases realistas y no sobre el voluntarismo, que es lo que está ocurriendo". (El País, 5 de noviembre de 2005) Antes de salir de Washington G. W. Bush había reconocido que el proyecto del ALCA estaba en "un punto muerto"y que la prioridad era el ciclo de Doha de la OMC, cuyas próximas negociaciones tendrían lugar en diciembre en Hong Kong. Mientras tanto Estados Unidos desea adelantar las negociaciones de tratados de libre comercio con Colombia, Ecuador y Perú similares a los ratificados con Canadá, México, Chile y los gobiernos de Centroamérica.

Tampoco ha sido muy amigable el encuentro entre el anfitrión Nestor Kirchner y George W. Bush, a quien pedía un apoyo en sus negociaciones con el FMI. Bush expresó que Buenos Aires es bastante "fuerte" para negociar sólo. Más tarde el presidente argentino en su discurso de apertura de la cumbre no ha dudado en denunciar la "inexcusable" responsabilidad de los Estados Unidos en la defensa de políticas que han provocado "miseria y pobreza", denunciando de paso el papel del FMI en estas políticas. "En nombre de la democracia nosotros tenemos menos democracia". Estas divisiones continentales han ocultado lo que era el punto central de la cumbre: la lucha contra la pobreza y el desempleo. ("La Cumbre de las Américas peligra fracasar". Le Monde, 5 de noviembre de 2005) El diario El Mundo de Madrid, comenta que "Mercosur insistió en que el ALCA no constituye el marco de equidad y acceso efectivo a los mercados que necesitan los países en desarrollo". (El Mundo, 3 de noviembre de 2005) Sin duda, éste era uno de los puntos claves del borrador inicial del ALCA en 2003, reformado para evitar la quiebra de la sesión de Miami: la falta de equidad y acceso efectivo a los mercados que necesitan los países en desarrollo. "El libre mercado es muy importante a condición de que respetemos el principio de igualdad entre las naciones", afirmó Lula de Silva.

\section{El escenario en que nace y se mueve el ALCA}

La Cumbre del Milenio, organizada por Naciones Unidas, tiene lugar en septiembre 2000 y la reunión de Quebec, donde se presenta el programa

Realldod 106, 2005 
del ALCA, se realiza en el mes de abril 2001. La 'letra pequeña' de este programa, los dieciocho objetivos sociales, es casi una copia literal de la Declaración del Milenio, es decir, contienen un pacto social que complementa al tratado comercial. El borrador inicial del ALCA 2003 se ha desprendido de todos esos compromisos sociales (que mencionaremos más adelante) y da por supuesto que emanan espontáneamente del evangelio del libre comercio. Esta será una de las causales de la confrontación en Miami 2003 y en Mar del Plata 2005.

Por otra parte, en la cumbre de la OMC en Seattle estalla "El malestar de la globalización" (Joseph Stiglitz) cuando los delegados de los países emergentes y en desarrollo se niegan a firmar un documento final, que ni tuvieron tiempo de leer. Esto significa que la Organización Mundial del Comercio pierde credibilidad en Seattle, diciembre 1999, y la vuelve a perder en la OMC del Desarrollo en Cancún, septiembre 2003. Por ello, en la cumbre del ALCA celebrada en Miami en 2003 se firmará "un ALCA a dos velocidades", que comentaremos más adelante. No puede entenderse la historia de los tratados de libre comercio, ni del ALCA, fuera de la historia de las cumbres de la OMC. Necesariamente, en Mar del Plata debía esperarse una seria confrontación entre MERCOSUR y Merconorte, cuando ya se prevén serias tensiones mundiales en la OMC de Hong Kong, diciembre de 2005, en torno a los compromisos de DohaQatar. Si durante cuatro años, pese a una serie de cumbres mundiales, los expertos, los ministros y los jefes de Estado no han llegado a un acuerdo en los puntos espinosos de Doha-Qatar, quiere decir que el comercio internacional realmente es "la batalla económica que se avecina", de Lester Thurow.

Podemos proyectar tres momentos de este video del ALCA para ver cómo se ha ido gestando esta confrontación intracontinental. En la reunión de Quebec, celebrada en abril de 2001, George W. Bush dijo: "Creo que el comercio es importante para este hemisferio. No sólo expande la prosperidad, sino que ayuda a expandir la libertad, un hemisferio democrático, ligado por la buena voluntad y el libre comercio". Algunos de los mandatarios coreaban al anfitrión: "El libre comercio sin subsidios ni prácticas desleales, acompañado de flujos crecientes de inversión productiva y de una mayor integración económica, favorecen la prosperidad regional, mejorando las condiciones laborales de los pueblos de las Américas y protegen el medio ambiente". Como himno suela bonito. 
No fue éste el parecer de Fernando Cardoso, presidente de Brasil, que en su discurso criticó las medidas antidumping de Estados Unidos y las asimetrías existentes en bienes agrícolas. "El ALCA será bienvenido si su creación significa un proceso para dar acceso a los mercados más dinámicos, si efectivamente significa el camino para las reglas compartidas antidumping, si reduce las barreras arancelarias, si evita la distorsión proteccionista de las buenas reglas sanitarias. Pero, si no es así, sería irrelevante o, en el peor de los casos, indeseable. Tanto Brasil como Argentina han insistido en la disminución de las barreras arancelarias y no arancelarias, que diezman las exportaciones regionales hacia Estados Unidos. Fernando Cardoso mostró su simpatía por las manifestaciones que critican "una globalización sin rostro humano". Criticó al presidente Bush por no haber querido ratificar el protocolo de Kyoto. Los manifestantes reunidos en Quebec coreaban desde los extramuros de la cumbre: “El proyecto del ALCA es un estatuto de derechos y libertades para los inversionistas, consagrando la supremacía del capital sobre el trabajo, transformando la vida y el mundo en mercancía, negando los derechos humanos, saboteando la democracia y socavando la soberanía de los Estados". (ECA 2001, pp. 710-714)

Dos años más tarde, septiembre 2003, en la "OMC del Desarrollo" en Cancún hay tres grupos de manifestantes: campesinos mexicanos que han quedado sin trabajo porque el precio del má́z blanco subvencionado por Estados Unidos se redujo en $70 \%$ y unos diez millones de pequeños agricultores abandonan sus tierras; unos 200 manifestantes de Corea del Sur porque miles y miles de sus campesinos no pueden competir con el arroz subvencionado proveniente de Estados Unidos; campesinos de pequeños países africanos amuinados porque sus exportaciones de algodón no pueden competir con la subvención de $\$ 4.000$ millones entregados a los algodoneros norteamericanos. Vicente Fox debe saber que Robert Zoellick (EE.UU.) y Pascal Lamy (UE) dijeron al Grupo de los 20 (G-20): "¿qué nos ofrecen ustedes para que nosotros les ofrezcamos algo?" Ante la intransigencia de Estados Unidos y de la Unión Europea, quebró la OMC de Cancún. (Entorno económico mundial, UCA Editores 2003; p.258)

\section{La cumbre del ALCA en Miami, noviembre de 2003}

En este escenario tiene lugar la nueva reunión del proyecto ALCA. "Unos 25 mil activistas contrarios a la globalización se manifiestan en Miami opuestos a un proyecto que, según ellos, generará pérdidas de 
empleo, efectos catastróficos sobre el medio ambiente y disminución del monto de la jubilación. Un gran número de sindicalistas, ecologistas, obreros, trabajadores sociales, pacifistas y defensores de los derechos humanos han desfilado gritando "No al ALCA". Un comercio justo sí, el libre cambio no". (Le Monde, 22 de noviembre de 2003) "Lanzado hace diez años, el ALCA choca con bastantes resistencias. La fecha tope, enero de 2005, está muy cerca. Criticado en América Latina por los adversarios de la mundialización neoliberal, que lo ven como un proyecto que favorece a las multinacionales, el ALCA también es criticado por los sindicatos y altermundialistas de Estados Unidos. A diferencia de la comunidad europea que reunía en sus comienzos países relativamente homogéneos, son inmensas las diferencias entre la economía de Estados Unidos y la del resto de los países latinoamericanos".

Para evitar confrontaciones que generaron el fiasco de la OMC de Cancún "los dos copresidentes de las negociaciones, Robert Zoellick, de EE.UU:, y Celso Amorim, de Brasil, redujeron el tono de sus discursos". Antes de ir a Miami elaboraron "un acuerdo a la carta", el cual recibió el aval de los ministros de comercio de las Américas. De esta forma adelantaron el cierre de la conferencia. El acuerdo permite a cada país signatario no adherirse a las cláusulas del ALCA que estime contrarias a sus intereses. Además permite seguir avanzando al hacer a un lado los asuntos espinosos, como las subvenciones agrícolas. Estados Unidos rechazó tratar este tema en Miami y dijo que sólo lo trataría en el seno de la Organización Mundial del Comercio. Otro punto es la salud pública. El acceso a medicamentos genéricos permitiría frenar la progresión del SIDA a menor costo. La confrontación no se suprime, se pospone. Prueba de ello es que, antes de terminar la reunión de Miami, Zoellick anunció la apertura de negociaciones bilaterales con Colombia, Perú, Ecuador, Panamá. La estrategia de Estados Unidos es aislar a Brasil, dado que esos países mantienen mayores transacciones con Estados Unidos que con MERCOSUR. Por otra parte, están las ayudas especiales concedidas a estos países para combatir la droga y el terrorismo. El gobierno claramente opositor en Miami fue el de Hugo Chávez, que calificó al ALCA como "proyecto colonial". (Ibidem, pp.275.)

En las mismas páginas puede leerse la introducción a la Deciaración Ministerial firmada en Miami, "a fin de proporcionar una orientación para la fase final de las negociaciones del ALCA". Además de "la letra pequeña' del acuerdo, anuncia que se han creado ocho grupos de 
negociación sobre temas espinosos, más tres cuerpos consultivos. La declaración ministerial detalla otros puntos importantes como las negociaciones relativas al acceso a los mercados, diferencias en los niveles de desarrollo y tamaño de las economías, los programas de cooperación hemisférica, la transparencia y participación de la sociedad, el calendario de las reuniones.

Una de las principales diferencias entre las negociaciones bilaterales seguidas en el TLC centroamericano con Estados Unidos y el proceso pactado en el ALCA es que, debido a las presiones de MERCOSUR, se han creado ocho grupos de negociación sobre 'temas espinosos': acceso a los mercados, agricultura, inversiones (AMI), política de competencia, derechos de propiedad intelectual, servicios, reglamento de diferendos, subvenciones, derechos antidumping y compensatorios. Además se han programado tres grupos auxiliares: grupo consultivo sobre economías pequeñas, comité de representantes gubernamentales sobre participación de la sociedad civil y comité técnico sobre cuestiones institucionales. Si en el ámbito mundial las negociaciones pendientes de la OMC de Doha están semiparalizadas, los expertos también piensan que, en un año, con dificultad se podrá llegar a acuerdos cerrados en estos grupos de negociaciones y comités consultivos. Y esto es lo que parece ha sucedido. (Ibidem, pp. 278.)

La tercera parte del vídeo sobre el ALCA es lo que hemos proyectado al presentar la reunión de Mar del Plata, que puede resumirse como "un acuerdo sobre desacuerdos". Parecería que el drama se hubiera centrado en dos actores: Vicente Fox se ha manifestado como el defensor del libre comercio internacional, a partir de su experiencia comercial con Canadá, Estados Unidos y otros países signatarios de tratados bilaterales, solicitando a los oponentes de MERCOSUR ser "más creativos". Vicente Fox parecía ser la voz del G. W. Bush, que mantuvo un cauto silencio. En el otro extremo Hugo Chávez se manifestó, con su típico estilo oratorio, contra Vicente Fox y contra el proyecto del ALCA, que para él sigue siendo un "proyecto colonial". Deducir de aquí que Vicente Fox sea un defensor del Comercio internacional y Hugo Chávez un crítico de cuartel, es falsear el problema. Ambos presidentes saben moverse muy bien en el escenario económico internacional. Vicente Fox, participando en enero 2001 en el foro económico de Davos, Suiza, no tuvo ningún reparo en ratificar un tratado de libre comercio con la Unión Europea, en un momento en que el estallido de la burbuja en la bolsa de valores de 
Nueva York había reducido su crecimiento a niveles cercanos a cero; no convenía colocar todos los huevos en el mismo canasto. Todos sabemos el papel que juega en el comercio intemacional el petróleo venezolano y la tenacidad de Hugo Chávez en lanzar la zona económica bolivariana. El ALCA no es simple y principalmente un acuerdo económico, sino un proyecto o una estrategia de dominación ideológica y política, incluso militar.

\section{Dos hechos novedosos en Mar del Plata}

Hay dos hechos novedosos que nos ayudan a entender el "acuerdo sobre desacuerdos". El diario francés Le Figaro presenta un artículo crítico del modelo económico: "Cumbre de las Américas: Bush en tierras hostiles". "Bush es casi el único blanco de millares de opositores". "Bush Go Home". "Jamás un presidente norteamericano había sido recibido con tanta animosidad en Argentina. Hace menos de diez años, Carlos Menen, mantenía relaciones calurosas con Estados Unidos. El modelo norteamericano ya no es una receta en su patio trasero. Una década de liberalización económica desenfrenada, orquestada por el FMI y BM con la bendición de la Casa Blanca, ha puesto de rodillas a las poblaciones latinoamericanas. América Latina tiene la impresión de haber sido víctima de un gran pillaje organizado por una asociación de malhechores, como las bancas internacionales, el FMI y ciertamente sus mismas élites. Un sentimiento que, en particular en los Andes, en Bolivia, en Perú, en Ecuador, donde los indígenas representan una parte importante de la población, resuena como pasados siglos de explotación. Ayer España, hoy Estados Unidos". (Le Figaro, 4 de noviembre de 2005).

No se trata sólo de la oposición al estéril modelo económico. Nuevos hechos generan la frontal oposición contra G. W. Bush; en este caso el ataque viene de un Premio Nobel de la Paz. En entrevista con el diario Le Monde, Adolfo Pérez Esquivel afirma: "Bush es un peligro para el mundo entero. Él no respeta ni la Declaración de los Derechos del Hombre, ni los pactos internacionales, ni el Consejo de Seguridad de Naciones Unidas. Invade países, miente al mundo y a su propio pueblo. Bush es responsable de crímenes de lesa humanidad, de masacres en Irak, en Afganistán y en la prisión de Guantánamo. Habla de terrorismo, pero rechaza que se denuncie el terrorismo de Estado de Estados Unidos. En América Latina Bush es una amenaza porque Norteamérica instala bases militares en todo el continente, Panamá, Colombia, Ecuador y en el Pacífico. Bush quiere imponer un acuerdo de libre comercio, el ALCA, 
pero el libre cambio sólo es una trampa, porque son los países ricos quienes controlan los precios y el desarrollo económico de los países pobres. La marcha del Mar del Plata contra Bush denuncia el pillaje de América Latina". (Le Monde, 4 de noviembre de 2005) Adolfo Pérez Esquivel ha sido delegado asistente a las reuniones anuales de un fenómeno que nos da otra visión del mundo.

A partir de 2001, se lanza en Porto Alegre el Foro Social Mundial. El número de asistentes es un reflejo de su impacto global: "Otro mundo es posible". Se congregan 20.000 personas en el foro de $2001 ; 50.000$ en 2002; 100.000 en 2003; cuando el foro social tiene lugar en Bombay, 2004, asisten unos 120.000 de 170 países diferentes, y en Porto Alegre 2005 se han vuelto a congregar unos 150.000 de acuerdo a algunos asistentes. En 2006 se proyecta congregar el foro social en algunos países de África.

"La historia es la siguiente: hartos de la crítica de que su única acción es la protesta, los críticos de una manera de entender la globalización y el liberalismo decidieron, a partir de este año, debatir y proponer altemativas al pensamiento único dominante. Y entendieron que había que hacerlo al mismo tiempo que sus antagonistas ideológicos para que los contrastes fueran explícitos, netos y tener la oportunidad de compararse." Joaquín Estefanía advierte que no todos los asistentes a Davos son neoliberales irredentos y los de Porto Alegre nostálgicos antisistema; en ambos lugares hay posturas intermedias, pero se puede decir que "a Suiza van los satisfechos y a Brasil los que no lo están. En el foro económico mundial se discute este año (2001) cómo sostener el crecimiento y disminuir las desigualdades, mientras que en Porto Alegre las ponencias tratan de construir un sistema de producción de bienes y servicios para todos, traducir el desarrollo científico en desarrollo humano, los fundamentos de la democracia humana y de un nuevo poder, o como asegurar el derecho a la información y a la democratización de los medios de comunicación". (Ibidem, p. 209)

"El foro social mundial pretende poner fin al pensamiento único y a la dominación del modelo mundial de las multinacionales, sustituyéndolo por un proyecto creible de progreso social y solidario. El programa de las redes temáticas se agrupa en los siguientes puntos: 1) Inventario de las principales alternativas que han tenido éxito. 2) Acciones para anular la deuda del Sur. 3) Propuestas de reforma de las instituciones financieras internacionales. 4) Nuevas reglas para el comercio internacional. 5) 
Mecanismos para controlar la especulación financiera internacional. El foro tiene vocación de permanencia y se ha fijado en diez años el horizonte de su primer balance". (Ibidem, p. 214)

En el foro social tenido en Bombay, enero de 2004, junto con los Premios Nobel de la Paz, Adolfo Pérez Esquivel, Rigoberta Menchú y Shirin Evadí, de origen iraní, aparecen el Premio Nobel de Economía, Joseph Stiglitz, Juan Somavia de la OIT, Shiva Vandani, ecologista de la India, el activista filipino Walden Bello, entre otros dando a entender que se trata, ante otros, de primeras figuras mundiales en sus respectivos campos. Se habló de la defensa de los derechos de la mujer, cuyas violaciones deberían ser objeto de deliberación y condena por parte de la Corte Penal Internacional. En la entrevista a Joseph Stiglitz se deja entrever que en Bombay, al analizar el comportamiento de la globalización, se criticó el imperialismo norteamericano y de manera concreta la invasión de Irak, Se discutió en algunos seminarios el tema del militarismo, la guerra y la paz y los oradores declararon "la guerra al imperialismo norteamericano".

La crítica más dura provino, al parecer, de la Premio Nobel de la Paz, Shirin Ebadí: "La invasión norteamericana es una de las cuestiones más importantes para este foro. Norteamérica, aduciendo la falta de democracia, ha atacado Irak, pero no se puede exportar la democracia. No se pueden exportar los derechos con bombas". Shirin Ebadí pidió que Estados Unidos y los países que apoyaron a Saddam respondan ante el Tribunal Penal Internacional. "Debemos enviar a Saddam Hussein al Tribunal Penal Internacional por los crímenes que cometió contra su propia nación, pero también contra la mía (Irán). Pero Estados Unidos y los Gobiernos europeos que colaboraron con él, son responsables y deben ser sentenciados en el mismo banquillo". Estos breves testimonios muestran la aversión a una globalización que suma al imperio económico "el derecho de la fuerza militar". (Ibídem, p.302-306)

Llegados a finales de 2005, deducimos que el Área del Libre Comercio de las Américas (ALCA) no es simplemente un tema y un problema del continente Alaska-Patagonia, sino que forma parte integrante de la economía global. En repetidas ocasiones el ALCA ha sido criticado y rechazado en las cumbres del foro social de Porto Alegre, en Brasil y en Bombay. El ALCA se inspira en la globalización neoliberal y es parte de un proyecto no sólo colonial, sino político militar. Ni el ALCA es sólo un proyecto económico, ni la invasión de Afganistán e Irak es sólo una estrategia militar. Lo político-militar está tan presente en el ALCA

609

En Mar del Plata y en Hong Kong, "la batalla económlea que se avecina" 
como lo económico en Irak; la reconstrucción de Irak es una piñata tan apetecida como el oro negro de su subsuelo. Es interesante que el inicio del ALCA coincida con la publicación de una importante obra de Comercio Internacional.

\section{La profecía de Lester Thurow}

Los buenos historiadores nos ayudan a movernos en los vericuetos de los siglos XX y XXI. En 1992, Lester Thurow publica la obra que citamos al principio, y en ella afirma: "La guerra fría ha terminado. Pero una nueva y feroz batalla ya ha comenzado. Con el colapso del comunismo en Europa del Este, la lucha por la supremacía estratégica entre los Estados Unidos y La Unión soviética se ha trasladado a una contienda por el dominio económico entre Japón, Europa y América. Lester Thurow ve esa guerra como una competencia entre el capitalismo centrado en el consumidor, propio de Estados Unidos, y el capitalismo centrado en el productor de Japón y Europa. Mientras Japón, Europa y América corren hacia el futuro compitiendo unos contra otros, "cabeza a cabeza", pronto sabremos qué teoría es la correcta, ya que al final el ganador determinará las reglas por las cuales se llevará a cabo el gran juego del capitalismo en las décadas que vendrán". El capítulo 8 plantea la pregunta: "¿Quién dominará el siglo XXI?".

El ALCA nace en este contorno de guerra económica, en abierta oposición a la teoría de que el libre comercio siempre beneficia a ambos intercambistas. Como recuerda P. Samuelson, maestro de maestros, gracias al comercio internacional todos los países pueden disfrutar y disponer de bienes-servicios que no pueden producir por sí mismos. Las empresas nacionales cuentan con más amplios mercados y pueden beneficiarse con mejores economías de escala y mayores niveles de empleo. Además, el comercio permite atender a los "gustos" de las poblaciones, punto importante a tomar en cuenta con los productos a exportar. El país que crea y dispone de nuevas tecnologías puede importar los insumos necesarios para generar exportaciones que por sí mismo no pudiera producir. Conviene agregar que la evolución del comercio internacional es el gran parámetro de la evolución de la economía mundial. Con razón se ha sustituido el título de comercio internacional por la expresión Economía Internacional. Siendo todo esto cierto volvemos a plantear la misma pregunta: ¿Por qué el libre comercio mantiene las características de una "guerra económica" o, como suele decirse, de una "paz violenta"?. ¿Qué cambios se han dado en el comportamiento del comercio internacional?

\section{0}

Realldad 106, 2005 


\section{Detrás del comercio está el modelo económico}

Tratando de buscar una explicación se me ocurre trasladar el "Preámbulo del Tratado de Roma", 1957, con el cual se constituye el Mercado Común Europeo.

"Su Majestad el Rey de los Belgas; el Presidente de la República Federal Alemana, el Presidente de la República Francesa, el Presidente de la República Italiana, Su Alteza Real la Gran Duquesa de Luxemburgo, Su Majestad la Reina de los Países Bajos, resueltos a sentar las bases de una unión cada vez más estrecha entre los pueblos europeos; Decididos a asegurar, mediante una acción común, el progreso económico y social de sus respectivos países, eliminando las barreras que dividen a Europa; Fijando como fin esencial de sus esfuerzos la constante mejora de las condiciones de vida y de trabajo de los pueblos; Reconociendo que la eliminación de los obstáculos existentes exige una acción concertada para garantizar un desarrollo económico estable, un intercambio comercial equilibrado y una competencia leal; Preocupados por reforzar la unidad de sus economías y asegurar su desarrollo armonioso, reduciendo las diferencias entre las diversas regiones y el retraso de los menos favorecidos; Deseosos de contribuir, mediante una política comercial común, a la progresiva supresión de las restricciones a los intercambios internacionales; Pretendiendo reforzar la solidaridad de Europa con los países de Ultramar y deseando asegurar el desarrollo de su prosperidad, de conformidad con los principios de la Carta de las Naciones Unidas; Resueltos a consolidar; mediante la constitución de este conjunto de recursos, la defensa de la paz y la libertad, e invitando a los demás pueblos de Europa, que participan de dicho ideal, a asociarse en su esfuerzo, han decidido crear una Comunidad Económica Europea".

Conviene recordar que los seis países firmantes se habían visto inmersos, doce años antes, en la más cruel segunda guerra mundial, con los horrores humanos, destrucciones físicas que gestó en todas estas naciones el conflicto armado. Esto ayuda a entender la terminología literaria de este Tratado de Roma, que se firma cuando el modelo económico de estos países es la Economía Social de Mercado en Alemania Occidental y el Estado Social de Bienestar en el resto de Europa Occidental. Lo importante es entender que en estos países se crearon ambos modelos a modo de terceras vías entre la economía de libre mercado, que quiebra globalmente en 1930, y los regímenes política y militarmente centralizados del nacional socialismo y del comunismo

611

En Mar del Plata y en Hong Kong, "la botalla econdmica que se avecina" 
soviético. Hay un abismo entre la inspiración económica social del inicial Tratado de Roma y la imagen de un proyecto colonial que parece haber inspirado a Bush padre y Bush hijo en Miami 1994 y en Quebec 2001. Aunque la inspiración económica explica en buena parte el rechazo a la ratificación del ALCA, también se han dado grandes cambios en la estructuración de la guerra económica, de que nos habla Lester Thurow.

Por lo que se refiere a Europa, los representantes de Austria, Suiza, Noruega, Suecia, Dinamarca, Portugal y Reino Unido firman en 1959 la Asociación del Libre Comercio de Europa (EFTA, por sus siglas en inglés). En 1972, Dinamarca, Irlanda y el Reino Unido firman el Acta de Adhesión a la Comunidad Europea. En 1981 Grecia firma el acta de adhesión a la Comunidad Europea y en 1985 lo hacen España y Portugal. En 1985 Mijail Gorbachov es elegido Secretario General del Partido Comunista Soviético, iniciando el proceso de la glasnost y perestroika. En 1986, se aprueba el Acta Única Europea, que entraría en vigor en julio 1987: libre circulación de bienes, servicios, capitales y personas. En 1990, se firma el Tratado de la Unificación de Alemania. En 1991, se crea la Comunidad de Estados Independientes, tras la extinción de la URSS. En 1992, se firma el tratado de Maastrich, que define las fases de la Unión Económica y Monetaria. En 1994 Austria, Finlandia y Suecia firman su adhesión a la Comunidad Europea. En los años siguientes se van firmando nuevos tratados de políticas económicas, el marco financiero 2000-2006 y los criterios para la futura ampliación de la Unión Europea. (Varii. Estructura económica mundial, E. Síntesis, Madrid 2001; pp. 455 y 464) Hacia final de siglo, como indica Lester Thurow, la Unión Europea tendrá unos 850 millones. Estamos hablando de un bloque económico tan fuerte como Estados Unidos: "head to head". Estamos hablando de una Unión Europea que es parte integrante de la globalización neoliberal, aunque Anthony Giddens le dedique La tercera vía: La renovación de la socialdemocracia. (Taunus, Madrid, 1998)

Luego de la segunda guerra mundial y con la supervisión militar de Estados Unidos se desarrolla la economía japonesa con un fuerte entrelazamiento del Estado y la estructura empresarial, en un empuje patriótico que entiende la empresa como una especie de familia económica y se afianza en el eslogan de consuma lo que el país produce. Japón pasa a ser la segunda potencia económica mundial y se venga de las bombas Hiroshima-Nagasaki con el creciente superávit de su balanza comercial con Estados Unidos. En la misma cuenca del Pacífico se desarrollan las 
economías mixtas de los tigres y dragones, donde se inicia la crisis financiera de 1997 por efecto especulación. En la cumbre de Doha 2001 ingresa China en la Organización Mundial del Comercio, como también lo saben por experiencia propia Estados Unidos y la Unión Europa. Se completa el título de Lester Thurow.

Si Lester Thurow habla de "la batalla económica que se avecina" ello se debe, en buena parte, a que en 1992 la economía mundial está en crisis. Utilizando una expresión bastante conocida, "la onda larga descendiente de Kondratief se resiente en los años de 1970-1980 y 1989. Las tasas de crecimiento del PIB en los países de la OCDE (industrializados) son las siguientes: $1960-68=5,1 \% ; 1968-1973=4,7 \% ; 1973-1979=2,6 \%$; $1979-1988=2,2 \%$. La revista del FMI (1992) recogía en sus grandes titulares algunos de estos signos de recesión: "El comercio internacional registró el crecimiento más pequeño desde 1983". "El crecimiento de la economía mundial será de $1,5 \%$ en 1992". "Estudio de la OCDE prevé un aumento del desempleo en 1992". "La hiperinflación en las antiguas economías de planificación central". "Es necesario reforzar medidas que fomenten la recuperación económica mundial". "El déficit, el paro y la inflación crecen en la mayoría de los países desarrollados. La locomotora alemana creció sólo un 1,5\% y los cinco sabios pronostican un crecimiento cero para 1993". "Mala salud de hierro" era el calificativo que los analistas aplicaban a la economía de los Estados Unidos, que se niega a recuperarse de la recesión de 1991-1992. Lester Thurow habla del derrumbe del sistema bancario e instituciones de ahorro de Estados Unidos, evitado gracias al salvavidas del Estado. (p. 21)

Se pudiera con estos títulos prolongar la lista de signos significativos de una prolongada recesión que, en el fondo, ponía de manifiesto que ninguno de los grandes modelos económicos -ocupados con la guerra fría- había dado una respuesta humana a los grandes problemas económicos, sociales, humanos e incluso ecológicos del primero, segundo y tercer mundo. En 1992 ya estamos en plena era de la globalización, que no tiene ningún derecho a proclamarse 'el fin de la historia'. En este escenario de crisis económica prolongada, en que se tiene la primera reunión, Miami 1994, para lanzar la idea del ALCA y en que el GATT se transforma, 1995, en la Organización Mundial del Comercio, vamos a descubrir que el libre comercio se caracteriza por profundas relaciones asimétricas, que justifican la expresión de Lester Thurow: "la batalla económica que se avecina entre Japón, Europa y Estados Unidos", ahora con una nueva inflexión entre países desarrollados y en vías de desarrollo.

613

En Mar del Plala y en Hong Kong, "la bolalla económlca que se avecina" 


\section{El TLC y el ALCA a la luz del entorno económico mundial}

Nuestros Tratados de Libre Comercio y el Área del Libre Comercio de las Américas nacen en un determinado entomo económico mundial y en plena era de una globalización neoliberal. Estos tratados no se discuten solo en determinados encuentros en Quebec, Miami, Mar del Plata, Seattle, Doha-Qatar, Cancún, Hong Kong, sino que historiadores, expertos, premios Nobel de economía y las mismas Naciones Unidas, les han ido dedicando un continuo análisis, que se traducirá en otros tantos documentos que van formando conciencia de sus efectos positivos y adversos para las diversas clases sociales. Fruto de esta toma de conciencia es que, junto con los expertos, ministros y jefes de Estado y de gobiemo, aparezcan también los manifestantes como la voz de los que no tienen voz. Al hacer memoria de algunos de estos momentos de reflexión, necesariamente nos tenemos que limitar a unos breves comentarios, con sus citas bibliográficas, que nos ayuden a formar conciencia de los claroscuros del libre comercio internacional.

\section{La Cumbre del Desarrollo Social, Copenhague, 1995}

La cumbre sobre el desarrollo social organizada por la ONU en Copenhague, marzo 1995, presenta un logotipo novedoso: "Las sociedades prósperas son las que existen en función del ser humano". Pero la realidad es muy distinta y los documentos de antecedentes nos presentan datos lacerantes de tres grandes problemas mundiales: "la pobreza se ha generalizado, disminuye el empleo productivo y crece la insolidaridad y la atomización social". Los grandes titulares son: Las sociedades se atomizan y se multiplican toda clase de delitos. El desempleo se globaliza. El agujero de la pobreza. Más población y más pobreza. Postdata a la cumbre de Copenhague: la contradicción principal de la cumbre radica en que, por un lado, los jefes de Estado dicen que quieren erradicar la pobreza, pero, por el otro lado, no pueden desembarazarse del esquema neoliberal. (Entomo económico mundial, pp. 85-91)

\section{9. “El neoliberalismo en América Latina”, 1996}

En noviembre de 199618 superiores provinciales de la Compañía de Jesús firman un documento: "El neoliberalismo en América Latina", cuyo resumen puede verse en la revista Realidad ( ${ }^{\circ} 54$; pp. 757-763). Se trata de unas reflexiones ético-económicas sobre las consecuencias del neoliberalismo en nuestros países, desde México hasta Chile. "El mercado, de un instrumento útil y hasta necesario para elevar y mejorar la oferta y 
reducir los precios, pasa a ser el medio, el método y el fin que gobierna las relaciones de los seres humanos. Reconocemos que las medidas de ajuste han tenido también aportes positivos".

"Estos elementos, sin embargo, están lejos de compensar los inmensos desequilibrios generados: gran concentración de los ingresos, la riqueza y la propiedad de la tierra; multiplicación de masas urbanas sin trabajo o que subsisten en empleos inestables y poco productivos; quiebras de miles de pequeñas y medianas empresas; destrucción y desplazamiento forzado de poblaciones indígenas y campesinas; expansión del narcotráfico, basado en sectores rurales cuyos productos tradicionales quedan fuera de competencia; desaparición de la seguridad alimentaria; aumento de la criminalizad provocada no pocas veces por el hambre; desestabilización de las economías nacionales por los flujos libres de la especulación internacional; desajustes en comunidades locales por proyectos de empresas multinacionales, que prescinden de los pobladores... Aumenta el rechazo a la orientación económica general que, lejos de mejorar el bien común, profundiza las causas tradicionales del descontento popular: la desigualdad, la miseria y la corrupción. El neoliberalismo ahonda los problemas de la pobreza estructural: la inequidad o injusta distribución del ingreso y de la riqueza, la precariedad del capital social y la desigualdad o la exclusión en las relaciones de intercambio" (Entorno económico mundial; pp. 97-105)

\section{0. "El huracán de la globalización", Franz Hinkelammert, 1997}

El buracán de La globalización se ha convertido en un título clásico, es decir, un artículo que debe leerse en clase En la introducción, Franz Hinkelammert nos hace una síntesis de la globalización: "El proceso de la globalización pasa desde hace más de dos décadas por encima de América Latina, así como pasa por encima del mundo entero, como un huracán. La privatización de las funciones del Estado, el libre comercio, el desencadenamiento de los movimientos internacionales de los capitales, la disolución del Estado social, la entrega de las funciones de planificación económica a las empresas multinacionales y la entrega de la fuerza de trabajo y de la naturaleza a las fuerzas del mercado han arrollado el continente". (Economía Informa. N $^{\circ} 255 /$ Marzo de 1997; PP. 11-19)

Hinkelammert presenta al primer mundo de hoy como "un archipiélago que aparece en todos lados, en el interior de un mar circundante de espacios que ya no pueden integrarse ni económica ni socialmente. Incluso 
los países del primer mundo dependen de un crecimiento intensivo, altamente tecnificado, que ha logrado los límites técnicos posibles y que puede seguir solamente al paso del surgimiento de nuevas posibilidades tecnológicas y de su aprovechamiento. Hoy día se habla de un tercer mundo al interior del primer mundo y de un primer mundo en el tercero. Esta relación no puede entenderse como una relación Norte-Sur, sino como una relación de exclusión. Esta apertura a la globalización tiene consecuencias negativas para la inversión de capital productivo en el área industrial, agraria o de las materias primas. Estas inversiones se pueden ver bloqueadas por el mismo proceso de la globalización. La producción de estas inversiones productivas requiere ser competitiva para poder realizarse, lo que pocas veces puede lograrse sin protección y fomento; en consecuencia no se inician. Los enclaves de este archipiélago conservan una dinámica hacia dentro y una exclusión de otras inversiones productivas. Así se explica la tendencia hacia la estagnación dinámica (jobless growth), el bloqueo al crecimiento del capital productivo, ante la libertad de flujos de mercancías, productos y capitales".

"Esto afecta de manera seria a múltiples inversiones internas productivas que, al verse frenadas, hacen que los capitales disponibles sean invertidos especulativamente. Aparece, entonces, la cacería de las inversiones especulativas de mayor rentabilidad. Estas posibilidades de inversiones especulativas se hallan sobre todo en los servicios públicos y sociales del Estado... Esto explica la presión mundial hacia la privatización de todas las funciones del Estado para encontrar esferas de inversión no productiva... Cualquier actividad humana tiene que ser transformada en esfera de inversión de capital para que pueda vivir el capital especularivo: escuelas, jardines infantiles, universidades, sistemas de salud, carreteras, infraestructura energética, el correo, las telecomunicaciones, los otros medios de comunicación".

"En América Latina la globalización acentúa la estagnación dinámica, donde el desarrollo se hace con menor fuerza de trabajo. Esta fuerza de trabajo "liberada" tiende a refugiarse en el sector informal, en situación de precaria subsistencia. Por tanto se discuten soluciones posibles a partir de estos dos problemas: exclusión de la población y destrucción del medio ambiente. En apoyo de esta política de exclusión se utiliza la teoría de las ventajas comparativas, ponderando siempre las ventajas y nunca sus pérdidas. Esta teoría sostiene que cualquier forma de comercio internacional necesariamente se aplica en ventaja de todos los países que 
entran en este comercio. Según esta teoría, no es posible que comprar barato sea la manera más cara de comprar. Sin embargo, la transición al estancamiento y después a la contracción dinámica son completamente diferentes. En esta situación el libre comercio destruye mayores ingresos de los que se generan derivados de la compra más barata. Efectivamente, se compra más barato, pero esta compra lleva a la destrucción de la producción que había permitido determinados ingresos. Al destruir esta producción, sin sustituirla por nueva y más eficiente, se pierde este ingreso sin ninguna contrapartida igual o mayor".

"Si la exclusión de la población resulta inevitable dentro de cualquier política de crecimiento, hace falta enfrentar la misma economía de crecimiento si se quiere una solución a este problema. La competitividad resulta en que siempre hay quien gana y quien pierde. Para quien pierde esto equivale a una condena a muerte. Competencia es una especie de guerra. Un desarrollo generalizado no es posible mas que al intervenir los mercados de una manera tal que aquel que pierda en la competencia no sea condenado a la muerte. Por esta razón el perdedor de la competencia tiene el derecho de protegerse y es bien racional el que lo haga. Al ser eliminado de la competencia pierde mucho más de lo que podría ganar con los efectos positivos de la competencia. Por tanto no debe aceptar el juicio del mercado.

Producciones no competitivas son económicamente racionales siempre y cuando las ventajas de la competencia —es decir, el acceso a bienes más baratos- sean superadas por las pérdidas de ingresos por medio de la eliminación de las producciones no competitivas. A modo de ejemplo, se expone el desarrollo de los tigres asiáticos, que no surgen por un sometimiento al proceso de la globalización, sino más bien utilizando la oportunidad que ella ofrecía: un entrelazamiento del Estado y de la estructura empresarial, que fomenta y protege las empresas nacionales para que puedan introducirse en el mercado internacional. Esta planificación económica utilizó los medios tradicionales para defenderse de la competencia externa y fortalecer sus ventajas competitivas. No ha sido ésta la política aplicada a nivel del continente latinoamericano". (Entomo económico mundial; pp. 113-116)

\section{La cumbre de la OMC en Seattle, EEUU, 1999}

Digamos que en Seattle estalla "el malestar en la globalización". Joseph Stiglitz inicia el primer capítulo de esta obra con una referencia a la 
cumbre de Seattle. "Las reuniones de oscuros tecnócratas en tomo a temas tan anodinos como los préstamos preferenciales o las cuotas comerciales se han transformado en escenarios de iracundas batallas callejeras y grandes manifestaciones. Las protestas en la reunión de Seattle de la Organización Mundial del Comercio en 1999 fueron una sacudida, pero desde entonces el movimiento ha crecido y la furia de ha extendido. Prácticamente todas las reuniones importantes del Fondo Monetario Internacional, el Banco Mundial y la OMC equivalen ahora a conflictos y disturbios. Lo nuevo es hoy la ola de condenas en los países desarrollados. Las protestas han provocado un enorme caudal de exámenes de conciencia desde el poder político. Incluso los políticos conservadores, como el presidente francés Jacques Chirac, han manifestado su preocupación porque la globalización no está mejorando la vida de quienes más necesitan de sus prometidas ventajas. Es claro para casi todo el mundo que algo ha funcionado terriblemente mal". (pp.27-28)

En la primera semana de diciembre 1999 tiene lugar en Seatcle, EEUU, esta reunión de la OMC, que va a tener una resonancia mundial por cuanto significa un enfrentamiento de los países en desarrollo frente a los países desarrollados y sus grandes empresas transnacionales por "la vía del desacuerdo". Actores principales de este evento han sido los manifestantes llegados de varias esquinas del mundo: ONG, ecologistas, sindicalistas y trabajadores. 50.000 manifestantes invaden las calles de Seattle, desbordan la policía y retrasan cinco horas la reunión de la OMC. "Abajo Babilonia", decía una pancarta. Para los manifestantes, "la OMC es la Babilonia del segundo milenio, una especie de siniestra organización de rostro anónimo, convertida en el motor de una globalización que sólo favorece a las grandes multinacionales". Los manifestantes dicen estar en la calle "para dar la palabra a aquellos que jamás la han tenido y para que la OMC escuche la voz de los ciudadanos. La ley de las multinacionales no es la democracia. Se trata de que los pequeños países se hagan escuchar. Gracias a la OMC por habernos puesto en movimiento", dicen los manifestantes.

En Seattle se lleva a cabo una versión ampliada de la batalla económica entre Japón, Europa y los Estados Unidos. El primer punto de confrontación es la redacción de la agenda de trabajo, donde surge una alianza entre Europa y Japón contra Estados Unidos. La Unión Europea busca sus aliados en los países del Este europeo; Estados Unidos busca el apoyo de unos 18 grandes exportadores agrarios, entre ellos Australia. 
Sindicatos y ecologistas piden que se preste atención a los daños causados por la expansión del comercio a las normas laborales, a la calidad de vida, a la ecología y a la estabilidad social y política. Distinta ha sido la postura de los gobiernos, organismos y empresas transnacionales que buscan la liberalización del comercio como un puente hacia el desarrollo económico, y que se oponen a que factores ajenos a los puramente económicos afecten los intercambios del mercado. Pese a las mutuas acusaciones va a quedar claro que tanto Europa como Estados Unidos subvencionan su agricultura y sus exportaciones agrícolas, y el Atlántico es testigo de las repetidas disputas sobre productos transgénicos, genéticamente modificados. En Europa la "política agraria común" (PAC) es considerable: 40,500 millones de euros; similares son las ayudas a los agricultores de Estados Unidos, aunque en forma menos visible: $\$ 22.000$ millones. En este proceso salen perjudicadas las exportaciones agrarias del Tercer Mundo.

En el foro económico mundial de Davos, enero 1999, los mismos organizadores del evento decían: "La gestión de los desafíos internacionales no puede seguir siendo monopolio exclusivo de las grandes potencias, a cuyas reuniones asisten los representantes y líderes políticos de las naciones emergentes como 'invitados de piedra'. En Seattle, los delegados de países industrializados pretenden mantener la tradición de las cumbres de la OMC, donde ellos programaban la agenda de la reunión, imponiendo temas que respondían a sus propios intereses. En la presente cumbre, el borrador de un pacto a firmar contenía los siguientes puntos: "sustanciales reducciones de las subvenciones agrícolas europeas, la creación de un grupo de trabajo sobre la biotecnología, la ampliación hasta 2001 de la moratoria sobre tasas de comercio en Internet, incremento de los intercambios en finanzas y telecomunicaciones y reforma de las leyes norteamericanas contra el dumping o competencia desleal". Se trata de puntos en litigio que mantenían en la sede de Ginebra los representantes de Estados Unidos, Europa, Japón y otros grandes países exportadores, como Australia.

En la normativa de la OMC el acuerdo final requiere el voto unánime de los 135 representantes de los países miembros. En Seattle triunfó el desacuerdo de los emergentes y de los países en desarrollo, que se negaron a firmar acuerdos finales cuando ni siquiera habían sido consultados y atendidos en la redacción de los previos borradores. La voz de los sin voz fue su desacuerdo, que ha sido interpretado como una victoria. Los países africanos denuncian acremente su marginación en todo el proceso de 
negociaciones. No hay transparencia alguna en este proceso y "Norteamericanos y Europeos juegan con nosotros con la política del palo y la zanahoria". Cuando las discusiones, a puerta cerrada, se eternizaban y no filtraba la menor información, los delegados de los países pobres, sin ánimo e ilusión, aguardaban pacientemente en los pasillos. "No sabemos qué decisiones se van a tomar y una vez más se nos pedirá suscribir un texto que ni tendremos tiempo para leer. La OMC ha sido, por fin, obligada a entrar en razón. No se puede proseguir la liberalización sin tomar en cuenta las preocupaciones de los ciudadanos". (Entorno económico mundial; p. 151-156)

El comercio internacional conserva su carácter de batalla económica.

\section{La letra pequeña del ALCA en la reunión de Quebec}

No está de más recordar que en la reunión de constitución del ALCA, celebrada en Quebec, se volvió a repetir el error de las 'negociaciones secretas', acremente criticado en Seattle. Dos comentaristas de dos reconocidos diarios critican esta secretismo, reconocido implícitamente por el presidente G. W. Bush. En su entrevista con el presidente argentino, Fernando de la Rúa, Bush insistió sobre el carácter democrático de la cumbre. "Luego de la reunión presentaremos el acuerdo, o su marco, a todos para que puedan estudiarlo y para que los ciudadanos de todos los países tengan la posibilidad -por primera vez en la historia- de examinar el texto de un acuerdo comercial". El problema es que todo el proceso se desarrolló en un ambiente secreto y las negociaciones han dado pie a críticas, alimentando las especulaciones. "La circulación de borradores, plagados de tachaduras, en nada ha ayudado a dar confianza, sobre todo después de la difusión del borrador sobre las "inversiones" (punto todavía en litigio), que autorizaría a las multinacionales a acusar a los gobiernos de poner límites a la libertad de comercio". La comentarista, Patrice de Beer, recuerda que el mismo Bill Clinton había recomendado a la OMC abandonar los métodos secretos y abrirse a la sociedad civil. Recomendación que no se ha seguido en Quebec. ("Comercio mundial y su entorno: el liderazgo de Estados Unidos discutido". Le Monde, 21 de abril de 2001)

José Vidal Beneyto, redactor de El País, recuerda que los manifestantes de la Cumbre de los Pueblos solicitaban "la transparencia en la preparación y en el relanzamiento del ALCA - los documentos sólo se conocieron al comenzar la reunión- a la par que la participación en los debates de las 
fuerzas políticas y sindicales, y también exigir que se incorporen al mismo temas esenciales como la garantía de los derechos y libertades individuales y colectivas, en particular de las mujeres y de las minorías étnicas; la protección del medio ambiente, la educación para todos y una economía sostenible". ("Dolarización panamericana". El País, 21 de abril de 2001)

A este fin se agregan una serie de objetivos, nada fáciles de lograr en el corto plazo y que traducen, casi al pie de la letra, los valores y principios de la Declaración del Milenio, septiembre 2000, de manera que lo más importante del ALCA es la siguiente letra pequeña, la que pocos han leído: "Transparencia en las relaciones entre las instituciones y los ciudadanos, dando mayor participación a la sociedad civil; cooperación en materia de derechos humanos; promoción de los derechos civiles, económicos, políticos y sociales de la mujer y de los pueblos indígenas; acceso universal a sistemas de justicia imparciales e independientes y la necesidad de recurrir a éstos para resolver conflictos; creación de prosperidad con la mayor zona de libre comercio del mundo, 800 millones de personas; promoción de los principios de inclusión y equidad, así como la mejora de las condiciones de trabajo, el respeto de las normas laborales y la cooperación en las cuestiones relacionadas con la migración; estudiar la adopción de iniciativas destinadas a garantizar la buena gestión de las empresas privadas y su responsabilidad social; mejorar los sistemas de transporte en el hemisferio; enfoques comunes en cuanto a la energía; estrechar la cooperación en cuestiones medioambientales; realización del potencial humano, que permita mejorar el nivel de vida de todos los ciudadanos, apoyando la iniciativa de reducir a la mitad, antes de 2015, el número de personas que viven en la pobreza, en todo el continente; acceso al empleo y facilitar que los ciudadanos adquieran las actitudes necesarias para competir en el contexto de una economía mundial, basada en el conocimiento; soluciones prácticas a la "brecha digital" existente en el hemisferio; enfatizar el acceso a la educación, la asistencia médica, así como proteger y promover la diversidad cultural". En total son 18 los compromisos que los gobiemos han pactado. "Agenda de la cumbre de Quebec". BBC Mundo, 19 de abril de 2001. "Libre comercio en 2006". El Diario de Hoy, 23 de abril 2001; p. 34. Revista ECA, 2001, № 633634; pp. 700-701)

El proyecto del ALCA es la letra mayúscula, aspectos relacionados con el intercambio comercial, y la letra pequeña, que integra el crecimiento económico con el desarrollo integral y sostenible. Parece que bastantes

621

En Mer del Plata y en Hong Kong, "la bolalla económleo que se aveclna" 
personas, incluidos jefes de Gobierno y ministros de los Ejecutivos nacionales, no entienden que el ALCA debe ser simultáneamente un tratado comercial y un pacto social, que difícilmente puede congeniarse con un esquema de economía neoliberal. Recordamos antes la afirmación de Lula da Silva: "El ALCA se convirtió en un debate ideológico y se dice que el que está en contra es de izquierda y el que está a favor es de derecha. Es un debate loco. Brasil sostiene que las negociaciones sobre el ALCA, que abandera Washington, pasan por discusiones previas, en el ámbito de la OMC, de asuntos como el fin de los subsidios agrícolas en los países ricos". (La Prensa Gráfica, 24 de noviembre de 2005; p. 43)

Si comparamos la letra pequeña del ALCA, incluida en el esquema de Quebec, con el borrador inicial del ALCA que debería tratarse en Miami, noviembre 2003, los delegados comerciales de Estados Unidos, Robert Zoellick y socios, habían desplumado al ALCA de casi todos los 18 puntos de un pacto social y lo habían reducido a un tratado comercial con todas las asimetrías propias de los Temas de Singapur y del Acuerdo Multilateral de Inversiones (AMI). (Este borrador del esquema ALCA aparece en la BBC de Londres. El Mundo, 21 de noviembre 2003. Cfr. "Un ALCA a dos velocidades". ECA 2003, N 663-664; pp. 146-148) Luego de Seattle Joseph Stiglitz había dicho que el libre comercio en poco o en nada ha beneficiado a los países en desarrollo, agregando que "la teoría del libre comercio es un fraude intelectual". Si el gobierno de Estados Unidos lo destituyó de su puesto de jefe de economistas del BM, al año siguiente J. Stiglitz fue galardonado con el Premio Nobel de Economía 2001 por su "teoría de las asimetrías".

\section{Mensaje de Joseph Stiglitz al G-7 reunido en Génova, julio de 2001}

Stiglitz aconseja a los miembros del G-7 no distraerse de los asuntos de largo plazo. "Entre ellos el más importante es la coordinación de las políticas económicas entre el Norte y el Sur, ya que en este punto el mundo se enfrenta no a una ralentización temporal sino a una crisis de larga duración... El sistema de comercio global está en problemas. Se predica el libre comercio como el evangelio en todas partes, pero parece que los países no hacen caso de su propio mensaje; sus mercados permanecen cerrados a muchos de los productos de los países en desarrollo, subsidian a sus agricultores en forma masiva, lo que hace imposible que los países en desarrollo puedan competir. El mensaje del G-7 parece ser: hagan lo que decimos, no lo que hacemos. Peor aún, los intereses económicos están por encima de todo, dejando de lado el delicado 
equilibrio de las políticas económicas y sociales. La Ronda de Uruguay de 1994, por ejemplo, estableció un régimen de propiedad intelectual que pone a los intereses de los propietarios por encima de los de los usuarios, incluyendo a los del mundo en desarrollo. Las compañías farmacéuticas insistieron en "sus derechos", aun si ello condenaba a las víctimas pobres del sida. La sociedad civil mundial finalmente ganó este punto, pero el régimen de propiedad intelectual no sufrió ningún cambio".

Aunque J. Stiglitz haya afirmado que "la teoría del libre comercio es un fraude intelectual", no significa que niegue la necesidad y los beneficios del comercio internacional, sino todo lo contrario. "El comercio puede ser un poderoso motor para el crecimiento económico, el cual es muy necesario en los países en desarrollo y poscomunistas. La ironía consiste en que mientras el G-7 impulsa los asuntos comerciales en ciertas dimensiones, no lo hace suficientemente en otras. He aquí algo que los ricos podrían hacer de inmediato: abrir totalmente sus mercados a todos los bienes y servicios de los países más pobres del mundo (a excepción de las armas)". Stiglitz admite que esta apertura podría generar algunos costos iniciales, pero las economías ricas se adaptarían y saldrían también beneficiadas, defendiéndose "de acusaciones de hipocresía que lanzan en su contra los países en desarrollo".

Stiglitz insiste en "la democratización del FMI y del Banco Mundial. Los intereses especiales y los intereses de los países ricos son demasiado dominantes. Dentro de los países del G-7, cuando se discuren problemas económicos no sólo participan los ministros de Finanzas y los dirigentes de los Bancos Centrales. Los trabajadores, los comerciantes y los consumidores también hacen oir su voz. Las organizaciones económicas multinacionales deben escuchar a todas las partes involucradas". Existe otro campo donde también se aplica la doble política y juega la doble moral: el papel del Estado. "La mayoría de los líderes del G-7 están comprometidos en casa con la búsqueda de un terreno intermedio entre un Estado demasiado dominante y la economía de laissez-faire. Aun cuando los mercados desempeñan un papel central, se deja una parte importante al gobierno. Desgraciadamente las organizaciones económicas internacionales se alejan de los principios democráticos internos de los países a los que supuestamente tratan de ayudar. Los retos son muy grandes. Algunos líderes del G-7 consideran que estas reformas son muy dolorosas. No obstante, todos tenemos mucho que perder sino se atacan estos problemas, ya que son asuntos que determinan el futuro de la 
economía mundial". (Un orden del día para el Grupo de los Siete". El País, 15 de julio 2001) El FMI, con fervor ideológico, receta a todos estos países el evangelio del libre mercado. (Ibídem; PP. 220-221)

\section{La batalla que se avecina desde la Conferencia Ministerial de Doha-Qatar}

Para evitar que se repitiera el fiasco de Seattle, cuyo fantasma estará presente en esta cumbre, después de varias sesiones se preparó un documento más claro de 9 páginas y 43 párrafos, donde se exponían los temas principales sometidos a discusión. Pese a la letra conciliatoria de la Declaración Ministerial, también en la cumbre de Doha tendremos una batalla económica. Los párrafos iniciales prometían la mayor atención a los problemas de los países en desarrollo y el estilo literario se presta a varias traducciones. He aquí unos breves párrafos de la Declaración Ministerial:

"La mayoría de los países de la OMC son países en desarrollo. Pretendemos poner sus necesidades e intereses en el centro del Programa de Trabajo adoptado en la presente declaración. Recordando el preámbulo del Acuerdo de Marraket (por el que se establece la Organización Mundial del Comercio), continuaremos realizando esfuerzos positivos para que los paises en desarrollo y especialmente los menos adelantados obtengan una parte del incremento del comercio internacional que corresponda a las necesidades de su desarrollo económico. Reconocemos la particular vulnerabilidad de los paises menos adelantados y las dificultades estructurales con que tropiezan en la economia mundial. Estamos comprometidos a bacer frente a la marginación de los paises menos adelantados en el comercio internacional y a mejorar su participación efectiva en el sistema multilateral de comercio. Continuaremos trabajando junto con las instituciones de Bretton Woods en pro de una mayor coberencia en la formulación de la política económica a escala mundial. Reafirmamos decididamente nuestro compromiso con el objetivo del desarrollo sostenible. Estamos convencidos de que los objetivos de respaldar y salvaguardar un sistema multilateral de comercio abierto y no discriminatorio y de actuar para la promoción del medio ambiente y la promoción del desarrollo sostenible pueden $y$ deben apoyarse mutuamente".

Enseguida veremos que la cumbre de Doha no fue tan amigable y que hubo que alargar de un día las sesiones para evitar que los países en desarrollo cerraran bruscamente la puerta. Lo importante para entender 
lo sucedido en la discusión del ALCA en Mar del Plata es que, gracias a la presión de Celso Amorín, ministro de Brasil, en la reunión de Miami 2003 se crearon ocho grupos de negociación para los temas espinosos que aparecen en la Declaración Ministerial de Doha y que - después de cuatro años- siguen sin resolución en espera de lo que pueda conseguirse en la ya próxima OMC de Hong Kong, que se anuncia algo confrontativa. No se podía ratificar en Mar del Plata un ALCA americano, con todos sus temas espinosos, sobre los cuales no puede haber un acuerdo mundial (OMC) por su carácter de relaciones asimétricas.

\subsection{El programa de trabajo}

\section{"Cuestiones y preocupaciones relativas a la aplicacion"}

"Agricultura" (12): "Reducciones de todas las formas de subvenciones a la exportación, con miras a su remoción progresiva; y reducciones sustanciales de la ayuda interna causante de la distorsión del comercio"

"Servicios" (15) "Las negociaciones sobre el comercio de servicios se llevarán a cabo con el propósito de promover el crecimiento económico de todos los interlocutores comerciales y el desarrollo de los países en desarrollo y menos adelantados. Reconocemos la labor ya realizada... y el gran número de propuestas presentadas por los Miembros sobre una amplia variedad de sectores y varias cuestiones horizontales, así como sobre el movimiento de personas físicas"...

"Acceso a los mercados de productos no agricolas". (16) Convenimos en celebrar negociaciones que tendrán por finalidad, según modalidades que se acordarán, reducir o, según proceda, eliminar los aranceles, incluida la reducción o eliminación de las crestas arancelarias, los aranceles elevados y la progresividad arancelaria, así como los obstáculos no arancelarios, en particular respecto de los productos cuya exportación interesa a los países en desarrollo. La cobertura será amplia y sin exclusiones a priori”...

"Aspectos de los Derechos de Propiedad Intelectual relacionados con el Comercio". (17) "Recalcamos la importancia que atribuimos a que el Acuerdo relativo a los Aspectos de los Derechos de Propiedad Intelectual relacionados con el Comercio se interprete y aplique de manera que apoye la salud pública, promoviendo tanto el acceso a los medicamentos existentes como la investigación y desarrollo de nuevos medicamentos y. A este respecto, adoptamos una Declaración aparte". 
"Relaciones entre Comercio e Inversiones". (20) "Reconociendo las razones a favor de un marco multilateral destinado a asegurar condiciones transparentes, estables y previsibles para las inversiones transfronterizas a largo plazo..., convenimos en que después del quito período de sesiones de la Conferencia Ministerial se celebrarán negociaciones sobre la base de una decisión que se ha de adoptar, por consenso explícito, en ese período de sesiones respecto de las modalidades de las negociaciones"....

"Interacción entre Comercio y Política de Competencia". (25) ."Se centrará en la aclaración de lo siguiente: principios fundamentales, incluidas la transparencia, la ausencia de discriminación y la equidad procesal, y disposiciones sobre los cárteles intrínsicamente nocivos: modalidades de cooperación voluntaria; y apoyo para el fortalecimiento progresivo de las instituciones encargadas de la competencia en los países en desarrollo mediante la creación de capacidad. Se tendrán plenamente en cuenta las necesidades de los países en desarrollo y menos adelantados participantes, y se preverá la flexibilidad apropiada para tratarlas".

"Transparencia de la Contratación Pública" (25): "Las negociaciones se limitarán a los aspectos relativos a la transparencia y por consiguiente no restringirán las posibilidades de los países de dar preferencia a los suministros y proveedores nacionales"...

Siguen otros temas como "Facilitación del comercio" (27); Normas de la OMC (28); Entendimiento sobre solución de diferencias (30); Comercio y medio ambiente (31); Comercio electrónico (34); Pequeñas economías (35); Comercio, deuda y finanzas (36); Comercio y transferencia de tecnología (37); Cooperación técnica y creación de capacidad (38); Países menos adelantados (42); Trato especial y diferenciado (44)...

\section{La batalla económica de Doha-Qatar, 2001 y de Cancún, 2003}

Doha-Qatar se desenvuelve bajo la sombra de Seattle. Se logran avances parciales en el campo de los medicamentos genéricos, pero el pacto sigue oscuro e impreciso como lo indicara J. Stiglitz. En "Agricultura" se logra una escurridiza promesa de "las reducciones de todas las formas de subvenciones a la exportación, con miras a su progresiva reducción". Los europeos no admiten la palabra "eliminación", y europeos y norteamericanos no han cumplido su promesa de reducción alguna cuando llegan a Cancún. El tema de las normas laborales y medioambientales queda en la sala de espera, al igual que los problemas espinosos de las 
inversiones (AMI), de la competencia y servicios. La cumbre de alarga de un día porque la India y otros países asiáticos presionan a Estados Unidos y Canadá para que reduzcan sus aranceles, de $23 \%$ a $3 \%$, a la importación de textiles, así como otros países exigen que la Administración Bush elimine el repentino arancel de $30 \%$ a las importaciones de acero. Esta es la hipocresía, dirá J. Stilgitz, de los defensores del libre comercio.

La cumbre de Doha se redujo a una serie de compromisos, que volverán a aparecer en la OMC de Hong Kong. La novedad mayor de la cumbre de Doha es que, después de quince años de discusiones, China entra a formar parte de la Organización Mundial del Comercio. Dos años más tarde el encuentro en Cancún es otro gran fracaso de la misma OMC. No hay que olvidar que los delegados de China, India y Brasil forman parte del Grupo de los 20 (G-20), que exigirán que Estados Unidos y la Unión Europea reduzcan, como habían prometido en Doha, sus masivas subvenciones ( $\$ 1.000$ millones diarios) a las exportaciones agrícolas. $\mathrm{La}$ respuesta de $\mathrm{R}$. Zoellick y P. Lamy fue: ¿qué nos ofrecen ustedes para que nosotros les ofrezcamos algo?

\section{El acuerdo marco de la OMC en Ginebra, 2004}

El primero de agosto 2004, se firma en Ginebra un acuerdo calificado de "histórico" por el director general de la OMC. Luego de cinco días de largos debates los 147 miembros de la OMC firman un acuerdo marco que introduce compromisos de serias reformas en cinco ejes del comercio internacional: subsidios a la agricultura, productos industriales, servicios, trabas burocráticas en las fronteras y ayudar a los países pobres. Los países industrializados aceptan no presionar en tres de los cuatro temas de Singapur: los mercados públicos, las inversiones y la competencia, obteniendo a cambio la simplificación de las normas y procesos aduaneros. El editorial de El País, "Compromiso crucial", afirma que "la OMC ha logrado evitar un desastre al acordar en Ginebra, contra reloj y en el último minuto, un compromiso que abre el camino a la reactivación del comercio mediante el recorte de las subvenciones agrícolas en los estados más ricos. (El País, 8 de agosto de 2004)

Se trata de una cumbre en la sede de la OMC que ha tenido menor resonancia, pero que los corresponsales de Le Monde califican como un "triunfo del multilateralismo". Pascal Lamy, entonces representante de Europa y hoy presidente de la OMC, se felicita "porque de nuevo el ciclo de Doha se ha encarrillado". R. Zoellick afirma: "Todo se ha hecho 
por consenso; si los países en desarrollo han aceptado el acuerdo, no es por filantropía ni debido a presiones; es simplemente por ser en interés de todos". Celso Amorim, que ha tenido un papel importante en estas negociaciones, dice que el acuerdo "es el comienzo del fin de las subvenciones". Su colega japonés comenta que después de Cancún el G20 "era considerado como un grupo subversivo, pero en Ginebra ha demostrado su poder de negociar y de lograr concesiones de los países del Norte". El embajador de China en la OMC cree que "de una manera general, el acuerdo no es malo, aunque los países en desarrollo no estén totalmente de acuerdo". (Le Monde, 2 de agosto de 2004)

Las primeras reformas se centran en la "agricultura". El acuerdo busca dar a los productores agrícolas de los países en desarrollo una mejor oportunidad de competir con los productos de los países desarrollados. "Competencia en la exportación" y a este fin se quieren corregir tres dispositivos criticados por los países pobres: "Las subvenciones a la exportación (utilizadas sobre todo por la Unión Europea); los créditos a la exportación (utilizados sobre todo por Estados Unidos) y los monopolios de exportación de empresas comerciales de Estado (casos de Canadá y Australia). "Todos los países miembros de la OMC tendrán que aplicar los mismos recortes una vez sea ratificado el acuerdo, para el que todavía no hay una fecha establecida. La única excepción son los 50 países más pobres de la OMC, que no tendrán que imponer esta medida. Este sistema también se aplicará para los aranceles que dificultan la entrada de productos agrícolas de otros países; los mayores recortes se los llevarán los productos más protegidos.

"Los servicios". El acuerdo en este apartado, aunque de gran importancia para los países ricos, sigue siendo ambiguo. Los países ricos desean liberalizar el sector de los servicios. Para ello el acuerdo prevé que cada país miembro haga las ofertas, es decir, informe a los otros países qué servicios esta dispuesto a liberalizar. El texto precisa que las ofertas concretas deben ser presentadas para el mes de mayo de 2005. Respecto a "las trabas aduaneras" el texto insiste en una reducción de las trabas burocráticas que entorpecen el tráfico de bienes en las fronteras. "Ayudas al desarrollo". Los 147 países miembros han pactado ayudar para que los países más pobres no se vean afectados negativamente por cualquier medida acordada en la OMC. "Productos Industriales". Los países más desarrollados piden, sobre todo a los países emergentes, reducir los aranceles con que se protegen de los bienes industriales producidos en el 
Norte. A cambio de las reducciones en las ayudas agrícolas, los países emergentes se han comprometido a recortar sus aranceles industriales, "aunque todavía no se han asignado porcentajes ni objetivos específicos".

En relación con los "temas de Singapur" los países desarrollados han aceptado dejar de lado, no insistir en tres de los cuatro temas adoptados en la OMC de Singapur, 1996: servicios públicos, inversiones y competencia. El texto propone abrir las negociaciones sobre el cuarto tema: facilitación de los intercambios, es decir simplificación de los trámites aduaneros. ("El comercio mundial se prepara para poner fin a los subsidios a la agricultura". El País, 2 de agosto de 2004. "Los principales puntos del acuerdo-marco de Ginebra". Le Monde, primero de agosto 2004) Ambos diarios trasladan otros artículos sobre este acuerdo marco aceptado, pero aún sin fecha de ratificación de parte de los 147 países miembros de la OMC. A decir verdad, no he encontrado muchas referencias en otros diarios y revistas a este acuerdo-marco de la OMC en su sede de Ginebra. $\mathrm{Ha}$ habido cambios en la presidencia de la OMC, ocupada hoy por Pascal Lamy, en los delegados de Estados Unidos y de la Unión Europea y de otros representantes nacionales ante la OMC. Lo que podemos observar es que, a dos semanas de la OMC en Hong Kong, el fantasma de Seattle planea sobre este rincón de China.

\section{Consternación, decepción y traición en la OMC de Hong Kong}

Aunque sólo quedan dos semanas para iniciar la cumbre de Hong Kong los últimos artículos no hablan simplemente de fracaso en el diálogo, de ausencia de una documento final satisfactorio. Las ONG preocupadas por el problema del desarrollo del tercer mundo presagian la consternación, la decepción y la traición que generará el mismo borrador preparado por Pascal Lamy. El diario madrileño El Mundo, afirma que la Comunidad Europea rechaza la propuesta de Lamy para la cumbre de la OMC. Quien rechaza la propuesta es Peter Mandelson, comisario europeo de Comercio. ¿Razón? "Hay progresos en Agricultura, pero no están correspondidos en los capítulos de bienes industriales y servicios. Esta falta de equilibrio constituye un problema real que es necesario resolver en Hong Kong". (El Mundo, 25 noviembre de 2003)

Si los países emergentes y en desarrollo vienen solicitando, desde la cumbre de Seattle 1999, que las Gobierno ricos reduzcan sus masivas subvenciones y aranceles agrarios, ahora son los países industrializados quienes piden a cambio que los países emergentes reduzcan sus aranceles

En Mes del Plato y en Hong Kong, "la batalla económlca que se aveclna" 
a los bienes industriales del Norte y abran sus servicios a la competencia extranjera. Nadie da nada por nada. En las dos siguientes semanas los negociadores deben centrarse en dos puntos bastante cercanos, la reducción de los derechos de aduana. Brasil, India y Argentina son muy prudentes en materia industrial, mientras que en materia agrícola la Unión Europea, los Estados Unidos y los países importadores del G-10, como Japón, Corea del Sur, Noruega, arrastran los pies. Los Europeos deben poner sobre la mesa unas ofertas mayores si quieren que Brasil y la India les correspondan en el campo industrial. Los interlocutores deben centrarse en diferentes dispositivos imaginados para ayudar a los páses en desarrollo. Uno de los dispositivos, la generalización de las supresiones de los derechos aduanales y cuotas sobre importaciones que provienen de los países menos adelantados, sigue siendo grave problema". (Le Monde, 28 de noviembre 2005)

Para las ONG encargadas del desarrollo de los países pobres "el programa del texto de Pascal Lamy levanta una ola de críticas". Según Coordinación del Sur, organización francesa que engloba unas cien ONG del desarrollo, el programa de P. Lamy "relega las cuestiones más vitales para 3.000 millones de personas que viven con menos de dos dólares al día, proponiendo —en nombre del desarrollo- una única solución: la liberalización de los mercados agrícolas, de los servicios y de los bienes industriales". A cambio de esto "no se propone ninguna solución para proteger los mercados agrícolas, sanear los mercados mundiales o tomar en consideración la baja estructural de los precios de las materias primas agrícolas, de las que vive la mitad de la humanidad". Este programa genera una triste "constemación".

Para Oxfam International, "es decepcionante ver a qué punto los países miembros están lejos de un acuerdo que ayude a los países pobres". El desarrollo "no está en el centro de las negociaciones". "Oxfarm reprocha, sobre todo a la Unión Europea (UE), de subordinar sus concesiones en materia de reducción del sostén a sus exportaciones al progreso en los otros sectores de la negociación, la liberalización del intercambio de servicios y de los productos manufactureros". En el texto de P. Lamy, "las negociaciones han marginado las demandas y problemas prioritarios de los países pobres". El programa Lamy "consagra la traición de las promesas (del ciclo de negociaciones) de Doha", "Ningún arreglo de último minuto podrá disimular el fracaso". Muchos países africanos se sienten decepcionados con las propuestas de Lamy, que no presentan 
ninguna ayuda a los productores africanos golpeados por las subvenciones masivas estadounidenses a sus productores de algodón. Queja que ya se expresó en la OMC de Cancún. "Este texto no tiene ningún contenido", deplora el embajador de Benin ante la OMC.

Nueve países ya han advertido en el proceso de las negociaciones la amenaza que pesa sobre el desarrollo de los países pobres. Otros ocho países (Brasil, Argentina, Indonesia, Namibia, Pakistán, Filipinas, Venezuela junto con África del Sur, han enviado a la OMC un texto pidiendo a los páses ricos que abran sus mercados a los productos agrícolas de los países pobres y reformar sus políticas agrícolas. "Los países desarrollados insisten en pasar la carga del ajuste (de sus agriculturas) sobre los países pobres", ha denunciado el embajador de África del Sur. Se preanuncia una triste conclusión. "Dado que no hay un acuerdo entre los Estados miembros sobre la agricultura, punto más espinoso de las negociaciones, Pascal Lamy ha renunciado desde comienzo del mes a su objetivo de concluir en Hong Kong las dos terceras partes de las negociaciones de Doha". La Coordinación OMC, que reúne a 24 ONG, han enviado una carta a Jacques Chirac: "Diez años bastan": ("10 ans ça suffit") "Le Monde, 29 de noviembre de 2005)

Algo funciona muy mal al terminar el primer quinquenio del nuevo milenio. El 18 del pasado mes de septiembre, lamentamos que los 191 miembros de Naciones Unidas no mostraron gran interés por dar cumplimiento a los objetivos de la Cumbre del Milenio. Nos preguntamos: ¿Por qué nos han decepcionado? (ECA, 2005; pp. 854-865) Al terminar el mes de noviembre, en Mar del Plata descubrimos que en nuestro continente hay "un acuerdo sobre los desacuerdos". Terminada la OMC de Hong Kong algunas ONG del desarrollo tendrán a bien recordarnos - tal vez el 26 de diciembre- los efectos mortales del "tsunami" del libre comercio internacional. 